\title{
FEASIBILITY AND FUNCTIONAL OUTCOME OF LAPAROSCOPIC NERVE SPARING RADICAL HYSTERECTOMY.
}

\section{Khaled Mohamed Ahmed Gaballa*; Adel Denewer, Ashraf Khater*, Fayez Shahatto*, Valerio Gallotta **,Giovanni Scambia**}

Surgical Oncology, Oncology Center Mansoura University, Mansoura, Egypt** and Gynecologic Oncology, Department of Gynecologic Oncology,Catholic University of the Sacred Heart,Rome,Italy

\section{ABSTRACT}

Aim: Evaluation of the feasibility of laparoscopic nerve sparing radical hysterectomy in comparison to the nonnerve sparing type.

Methodology:Patient recruitment started from November 2014 to November 2016, patients who underwent laparoscopic type C1 hysterectomy and laparoscopic type C2 hysterectomy according to Querleu-Morrow classification(1) at our departments were prospectively evaluated. The inclusion criteria included: Patients with cervical carcinoma Stage IA2 to stage IIB cervical cancer according to FIGO staging and Stage II-III endometrial cancer with cervical involvement according to FIGO staging. Postoperative drainage of the bladder through a Foley catheter was maintained for 2 days and removed on the third day and the patients were asked to perform spontaneous voiding every 3 hours followed immediately by drainage of the bladder by urinary catheter to assess the post void residual (PVR) urine volume. The procedure was repeated until the PVR is less than 100 $\mathrm{ml}$. The voiding function was considered normal when the patient had 2 consecutive measurements of PVR urine less than $100 \mathrm{ml}$ and abnormal if the patient had a PVR urine more than $100 \mathrm{ml}$ with need of self- catheterization after 4 weeks from the date of surgery.

Results:46 patients were included in the study, 30 patients underwent type C1 LNSRH (Group A) and 16

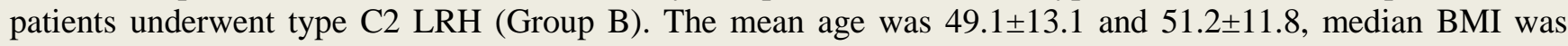
26.2(22.9-28.5) and 23.8(21-26.6) respectively for the 2 groups. The mean operative time was $240.1 \pm 65.5$ in group $\mathrm{A}$ and $308.1 \pm 83$ in group $\mathrm{B}$ ( $\mathrm{P}$ value $=0.004$ ). The rate of intraoperative complications was $10 \%$ in group $\mathrm{A}$ and $12.5 \%$ in group B. The median duration of postoperative catheterization until the PVR urine volume was less than $100 \mathrm{ml}$ was 3.5(3-5) days in group A and 6(4-8.5) days in group B (P value=0.002), The rate of late postoperative complications including bladder dysfunction was 3.3\% (Group A) and $31.25 \%$ (Group B) (P value 0.002).

Conclusion:Our study results supported the feasibility of LNSRH technique with better functional outcome without compromising the oncologic safety of the procedure

Corresponding author: Khaled Mohamed Ahmed Gaballa

Email: Khaledgaballah85@gmail.com

Mailing address: Gomhoria street, 70 ,Mansoura, DK, 35511, Egypt

\section{INTRODUCTION}

C ervical cancer is one of the leading gynecological malignancies with cancer related deaths in many countries worldwide. Cervical cancer has an estimated rate of 500,00 new cases and 273,000 related deaths per year(2). The golden standard for treatment of early stage cervical cancer has been the Wertheim's radical hysterectomy with pelvic lymphadenectomy for years(3). This technique had been accompanied by a number of drawbacks specially the bladder dysfunction postoperatively which had been concluded in several studies with rates up to $80 \%(4)$. The demanding need to improve the quality of life following this type of surgery lead to a number of trials concerning a nerve sparing technique to improve the postoperative outcomes which was developed in Japan in 60s(5). Several trials followed then aiming to improve the postoperative outcomes by better preserving the pelvic autonomic nerves during RH (6-9). Following the era of laparoscopy several authors published their work concerning the use of the nerve sparing technique rather than the conventional $\mathrm{RH}$ technique for better postoperative outcomes taking the advantage of laparoscopy in magnified view and meticulous dissection(10, 11). In our study we prospectively compare 2 groups of patients in 
whom we used type $\mathrm{C} 1 \mathrm{RH}$ nerve sparing technique according to Querleu and Morrow classification(1) in one group and type $\mathrm{C} 2 \mathrm{RH}$ in the other.

\section{MATERIALS AND METHODS}

Patient recruitment started from November 2014 to November 2016, patients who underwent laparoscopic type $\mathrm{C} 1$ hysterectomy and laparoscopic type C2 hysterectomy according to Querleu-Morrow classification(1) at the department of Surgical Oncology, Oncology center Mansoura university, Mansoura, Egypt and the department of gynecologic oncology, Catholic University of sacred heart Rome, Italy were prospectively evaluated. The study was registered at clinical trials.gov with code NCT02524756. The study was approved by Institutional Review Board and the Local Ethical Committee. A written consent with simplified explanation of the operation and the possible intra-operative and post-operative complications was signed by every patient prior to surgery.

The inclusion criteria included: (1) Patients with cervical carcinoma Stage IA2 to stage IIB cervical cancer according to FIGO staging and (2) Stage II-III endometrial cancer with cervical involvement according to FIGO staging. The exclusion criteria were (1) Patients with history or symptoms of bladder dysfunction detected prior to surgery. (2) Previous pelvic lymphadenectomy or previous pelvic surgery that could affect the integrity of the pelvic autonomic plexus. (3) Patients with metastatic disease prior to surgery (4) Patients with irresectable tumor or incomplete surgery and (5) Patients with recurrent disease.

The preoperative assessment of the patients included a detailed history, physical examination, preoperative pelviabdominal MRI or CT, examination under anesthesia and a tissue biopsy from the cervix or the endometrium, chest radiology according to FIGO stage and routine biochemical examinations.

Patients with locally advanced tumors were submitted to neoadjuvant therapy whether platinum based chemotherapy or chemoradiotherapy according to the tumor type prior to performing LNSRH. Patients with suspicious para-aortic $\mathrm{LN}$ in the preoperative radiology underwent para-aortic LN sampling during surgery. All the patients submitted to surgery had a prophylactic dose of Enoxaparin sodium (Clexane) the night before the operation.

After the surgery the patients were maintained on postoperative prophylactic Enoxaparin for 30 days. The patients started oral intake as soon as intestinal sounds are heard usually the same day of the operation. Postoperative drainage of the bladder through a Foley catheter was maintained for 2 days without performing bladder-training exercise. Foley catheter was removed on the third day and the patients were asked to perform spontaneous voiding every 3 hours followed immediately by drainage of the bladder by urinary catheter to assess the post void residual (PVR) urine volume. The procedure was repeated until the PVR is less than $100 \mathrm{ml}$. If the PVR urine was still more than $100 \mathrm{ml}$ on the $5^{\text {th }}$ postoperative day the patients were discharged with self-retaining urinary catheter and given a date after 3 days of discharge for trial of removal of the urinary catheter after measuring the PVR urine by the mentioned above procedure.

The voiding function was considered normal when the patient had 2 consecutive measurements of PVR urine less than $100 \mathrm{ml}$ and abnormal if the patient had a PVR urine more than $100 \mathrm{ml}$ with need of selfcatheterization after 4 weeks from the date of surgery.

Preoperative data (Age, BMI, FIGO staging, tumor histology, tumor grade, previous abdominal surgery and neoadjuvant therapy), surgical data (operative time, blood loss, intraoperative complications and rate of conversion to open technique), postoperative data including (length of hospital stay, duration for removal of urinary catheter, postoperative complications and adjuvant therapy) and follow up data including (tumor recurrence, bladder function questionnaire) were collected. 
STATISTICAL ANALYSIS

Statistical analysis: The extracted data were arranged in Excel spread sheet under Microsoft Windows (Bristol, UK) and all the statistical analyses were performed using STATA 12 (Statacorp LP, college station, TX). Categorical variables were reported as numbers and percentages. Continuous variables were described as mean \pm standard deviation (SD) or median and interquartile range (IQR) according to distribution. The Chi-squared test or Fisher's exact test was used to compare categorical variables, and Student's t test or Mann-Whitney $\mathrm{U}$ test was used when appropriate to detect differences between continuous variables. $P$ values less than 0.05 were considered to indicate statistical significance.

\section{RESULTS}

46 patients were included in the study, 30 patients underwent type C1 LNSRH (Group A) and 16 patients underwent type C2 LRH (Group B). The patients' demographics and perioperative data are summarized in table 1.

\begin{tabular}{|c|c|c|c|}
\hline Patient characteristics & Group A (C1) & $\begin{array}{c}\text { Group B } \\
(\mathrm{C} 2) \\
\end{array}$ & P Value \\
\hline Total number & 30 & 16 & \\
\hline Age mean \pm SD & $49.1 \pm 13.1$ & $51.2 \pm 11.8$ & 0.58 \\
\hline Types, n (\%) (cervix/endometrium) & $25 / 5$ & $16 / 0$ & 0.14 \\
\hline $\begin{array}{c}\text { BMI } \\
\text { Median (IQR) }\end{array}$ & $26.2(22.9-28.5)$ & $23.8(21-26.6)$ & 0.061 \\
\hline $\begin{array}{c}\text { Neoadjuvant therapy, } \mathrm{n}(\%) \\
\text { Yes } \\
\text { Type of NAT } \\
\text { Radiotherapy } \\
\text { Chemotherapy } \\
\text { Chemoradiotherapy }\end{array}$ & $\begin{array}{c}0 \\
1(25) \\
3(75)\end{array}$ & $\begin{array}{l}11(68.7) \\
0 \\
2(18.2) \\
9(81.8)\end{array}$ & $<0.0001$ \\
\hline $\begin{array}{c}\text { Pathology type, } \mathrm{n}(\%) \\
\text { Squamous cell carcinoma } \\
\text { Adenocarcinoma } \\
\text { Adenosquamouscarcinoma } \\
\text { Neuroendocrine carcinoma } \\
\text { Carcinosarcoma } \\
\end{array}$ & $\begin{array}{l}15(50) \\
8(26.7) \\
5(16.7) \\
0 \\
2(6.6) \\
\end{array}$ & $\begin{array}{c}13(81.2) \\
2(12.5) \\
0 \\
1(6.3) \\
0 \\
\end{array}$ & 0.083 \\
\hline $\begin{array}{l}\text { FIGO staging, } \mathrm{n}(\%) \\
\text { IB1 Cervical cancer } \\
\text { IB2 Cervical cancer } \\
\text { II endometrial cancer } \\
\text { IIA1 Cervical cancer } \\
\text { IIA2 Cervical cancer } \\
\text { IIB Cervical cancer } \\
\text { IIIB Cervical cancer } \\
\text { IIIC endometrial cancer }\end{array}$ & $\begin{array}{c}17(56.7) \\
3(10) \\
4(13.3) \\
1(3.3) \\
3(10) \\
1(3.3) \\
0 \\
1(3.3)\end{array}$ & $\begin{array}{cl}3 & (18.7) \\
& 0 \\
& 0 \\
& 0 \\
& 0 \\
1 & (6.3) \\
10 & (62.5) \\
2 & (12.5) \\
& 0\end{array}$ & \\
\hline $\begin{array}{l}\text { Table 1: Patients characteristics } \\
\text { All procedures were initially planned by } \\
\text { laparoscopy, only } 3 \text { patients (10\%) in group A } \\
\text { had unplanned conversion to laparotomy; one } \\
\text { patient due to difficult dissection of infiltrated }\end{array}$ & \multicolumn{3}{|c|}{$\begin{array}{l}\text { parametrium, one patient due to ureteric injury } \\
\text { which needed conversion to laparotomy for } \\
\text { repair and one patient with high BMI (57) due } \\
\text { to anaesthesia related problems during } \\
\text { trendlenberg position. } 4 \text { patients }(25 \%) \text { in group }\end{array}$} \\
\hline Khaled M., et al..... & & & $-299-$ \\
\hline
\end{tabular}


B had unplanned conversion to laparotomy; 2 patients due to difficulty in dissection of infiltrated parametrium, one patient due to difficulty in dissection of enlarged pelvic and paraaortic nodes and one patient due to ureteric injury which was repaired in laparotomy. The mean operative time was $240.1 \pm 65.5$ in group $A$ and $308.1 \pm 83$ in group B which was statistically significant with $\mathrm{p}$ value $=0.004$. The median blood loss was $100(50-150) \mathrm{ml}$ in group A and 125 (100-200) $\mathrm{ml}$ in group B. The mean number of harvested LN was 23.5 (18.428.6) in group A and 24.6 (16.9-32.4) in group B. The rate of intraoperative complications was $10 \%$ in group $\mathrm{A}$ and $12.5 \%$ in group $\mathrm{B}$. The 3 patients $(10 \%)$ in group $\mathrm{A}$; one patient had a bladder tear which was repaired by intracorporeal suture, one patient had a small rectal tear during dissection of the rectovaginal space which was prepared by laparoscopic suture and the last patient had a ureteric injury that required a conversion to laparotomy and repair of the ureter with insertion of a ureteric stent. The 2 patients $(12.5 \%)$ in group B both had a ureteric injury one of them had a partial tear which was repaired in laparoscopy with insertion of a ureteric stent by cystoscopy. The other patient required conversion to laparotomy with ureteric re-implantation into the urinary bladder. The operative data of the patients are summarized in table 2.

\begin{tabular}{cccc} 
Operative data & Group A (C1) & Group B (C2) & P Value \\
\hline $\begin{array}{c}\text { Operative time } \\
\text { Mean } \pm \text { SD }\end{array}$ & $240.1 \pm 65.5$ & $308.1 \pm 83$ & 0.004 \\
\hline $\begin{array}{c}\text { Blood loss } \\
\text { Median (IQR) ml }\end{array}$ & $100(50-150)$ & $125(100-200)$ & 0.0513 \\
\hline Conversion rate, $\mathrm{n}(\%)$ & $3(10)$ & $4(25)$ & 0.198 \\
\hline Intraoperative complication, $\mathrm{n}(\%)$ & $3(10)$ & $2(12.5)$ & 1 \\
\hline $\begin{array}{c}\text { Total harvested LN number } \\
\text { Mean (95\% CI) }\end{array}$ & $23.5(18.4-28.6)$ & $24.6(16.9-32.4)$ & 0.79 \\
\hline
\end{tabular}

Table 2: Operative data

The median duration of hospital stay in days was 3(3-4) in group A and 4(3.5-6) in group B $(\mathrm{P}=0.01)$. No mortalities have been recorded in both groups during the period of follow up. None of the patients of group A had an early postoperative complication within 30 days postoperative and 2 patients $(12.5 \%)$ in group B had an early postoperative complication; one patient after 10 days of the operation which had an infected pelvic collection due to urinary leakage from the left ureter that required exploration and open drainage with re-insertion of a ureteric stent and the other patient had a urinary infection with fever which was treated by antibiotics. Only one patient (3.3\%) in group A had a late postoperative complication which was ureteric stricture 8 months after the operation and was resolved by percutaneous nephrostomy $(\mathrm{PCN})$ and insertion of a ureteric stent. 5 patients $(31.25 \%)$ in group B suffered from a late postoperative complications more than 30 days postoperative. One patient had an urge incontinence, one patient suffered of both urge incontinence and left lower limb lymphedema, one patient had bilateral hydronephrosis due to subsequent ureteric stricture which required bilateral percutaneous nephrostomy, one patient had a vesicovaginal fistula 2 months after the operation which was managed temporarily by bilateral nephrostomy until the patient completes the adjuvant treatment and the last patient suffered of urinary retention 2 months after discharge from the hospital. The intra and postoperative complications of the 2 groups are illustrated in table 3 and graph 1. 


\begin{tabular}{|c|c|c|c|}
\hline & Group A & Group B & P value \\
\hline \multicolumn{4}{|l|}{ Intraoperative complication } \\
\hline $\mathrm{G} 2$ & $3(10 \%)$ & $2(12.5 \%)$ & 1 \\
\hline \multicolumn{4}{|l|}{ Ureteric injury } \\
\hline Bladder injury & 1 & 2 & \\
\hline \multirow[t]{2}{*}{ Rectal injury } & 1 & 0 & \\
\hline & 1 & 0 & \\
\hline $\begin{array}{l}\text { Total postoperative } \\
\text { complication }\end{array}$ & $1(3.3 \%)$ & $6(37.5 \%)$ & 0.002 \\
\hline $\begin{array}{c}\text { Early postoperative } \\
\text { complication (30 days post } \\
\text { operative) } \\
\text { G2 }\end{array}$ & 0 & $2(12.5 \%)$ & \\
\hline $\begin{array}{c}\text { Fever with UTI } \\
\text { G3 }\end{array}$ & 0 & 1 & \\
\hline Pelvic collection & 0 & 1 & \\
\hline $\begin{array}{c}\text { Late postoperative } \\
\text { complication }(>30 \text { days post } \\
\text { operative) } \\
\text { G2 }\end{array}$ & $1(3.3 \%)$ & $5(31.25 \%)$ & \\
\hline Urge incontinence & 0 & 2 & \\
\hline $\begin{array}{c}\text { Urinary retention } \\
\text { G3 }\end{array}$ & 0 & 1 & \\
\hline Ureteric stricture & 1 & 1 & \\
\hline Vesicovaginal fistula & 0 & 1 & \\
\hline Lymphedema & 0 & 1 & \\
\hline
\end{tabular}

Table 3: Intra and postoperative complications grading according to MSKCC grading (Memorial Sloan Kettering cancer center)

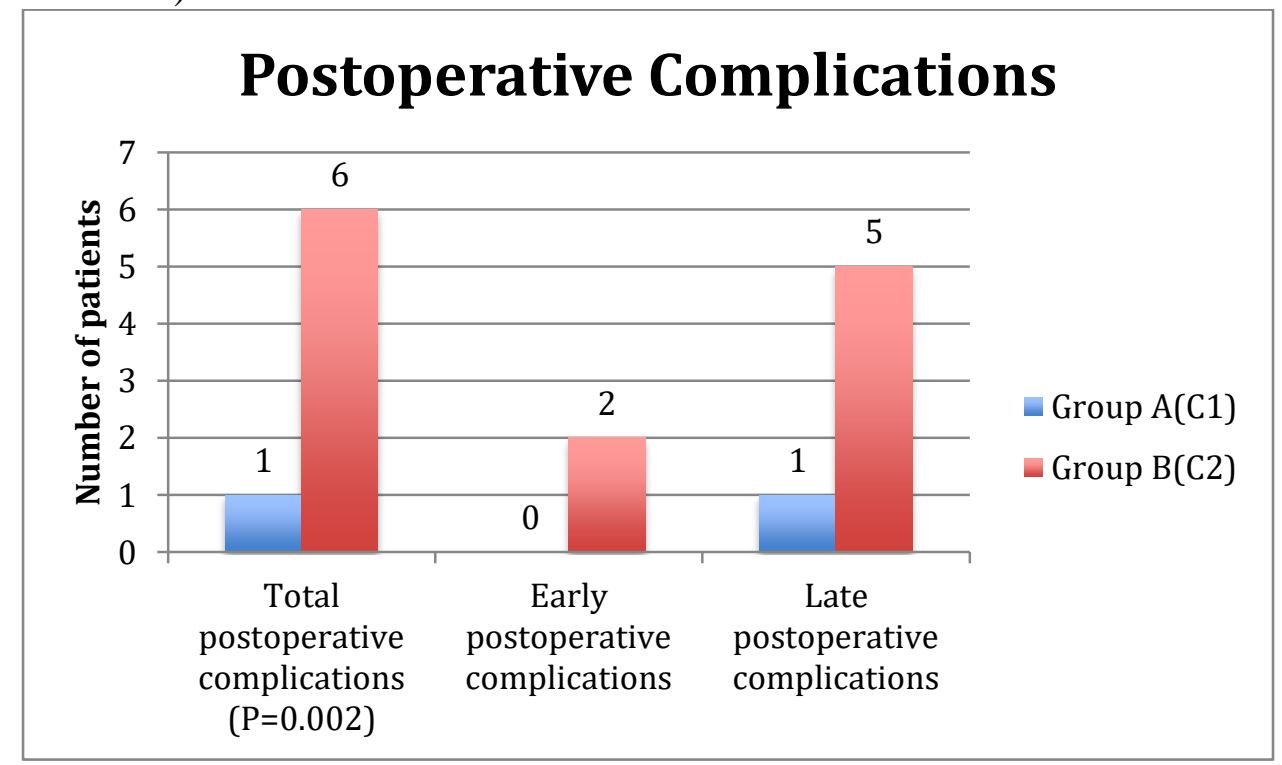

Graph 1: Postoperative complications 
The median duration of postoperative catheterization until the PVR urine volume was less than $100 \mathrm{ml}$ was 3.5(3-5) days in group A and 6(4-8.5) days in group B ( $\mathrm{P}$ value $=0.002)$ after excluding 2 patients one in each group in whom the bladder catheter was maintained for 14 days irrespective the volume of PVR due to bladder repair and ureteric re-implantation following intraoperative injuries.

\section{Median Duration of postoperative bladder catheterization in days $(P=0.002)$}

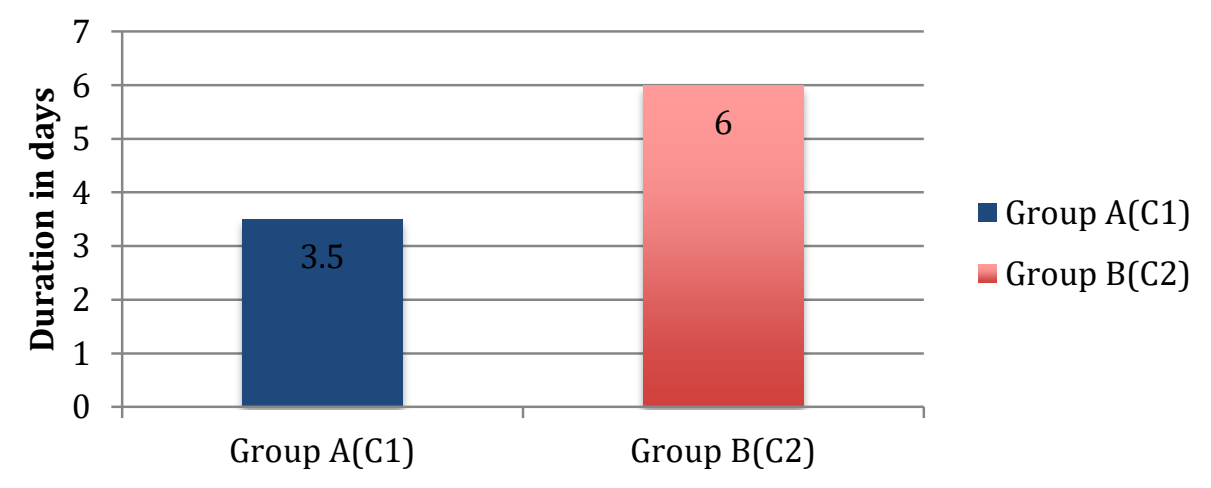

Graph 2: Median duration of postoperative catheterization.

The pathological diagnosis of all 46 patients in the 2 groups was similar to the preoperative diagnostic biopsy. 3 patients in group A and 4 patients in group B had a positive pelvic LN metastasis. 1 patient in each group had a positive para-aortic LN metastasis without pelvic LN metastasis. 21 patients in group A and 9 patients in group B received adjuvant therapy. Types of adjuvant therapy and LN status are summarized in table 4 .

\begin{tabular}{cccc} 
& Group A & Group B & P Value \\
\hline $\begin{array}{c}\text { Total harvested LN number } \\
\text { Mean (95\% CI) }\end{array}$ & $23.5(18.4-28.6)$ & $24.6(16.9-32.4)$ & 0.79 \\
\hline $\begin{array}{c}\text { Patients with Positive pelvic nodes } \\
\text { No.(\%) }\end{array}$ & $3(10 \%)$ & $4(25 \%)$ & 0.216 \\
\hline Patients with Positive para-aortic & & \\
nodes No. (\%) & $1(3.3 \%)$ & $1(6.2 \%)$ & 1 \\
\hline Adjuvant therapy No.(\%) & $21(70 \%)$ & $9(56.3 \%)$ & 0.351 \\
\hline $\begin{array}{c}\text { Radiotherapy } \\
\text { Chemotherapy } \\
\text { Chemoradiation }\end{array}$ & $\begin{array}{c}11(36.7 \%) \\
4(13.3 \%)\end{array}$ & $\begin{array}{c}2(16.7 \%) \\
3(25 \%) \\
4(33.3 \%)\end{array}$ & \\
\hline
\end{tabular}

Table 4: Postoperative LN status and adjuvant therapy.

The median duration of follow up was 15 months in group A and 16 months in group B. 4 patients (13.3\%) in group A and one patient in group B developed local or regional recurrence 
during the follow up period $(\mathrm{P}=0.645)$ (table 5). None of the patients developed distant metastasis during the period of follow up. The mortality rate was $0 \%$ in both groups during the period of follow up. All patients with recurrence were managed by chemotherapy.
Patients with isolated recurrence of vaginal cupola were followed by surgery None of the patients of group A complained of bladder dysfunction symptoms during the follow up period while 3 patients in group B had bladder dysfunction symptoms ( $\mathrm{P}=0.037$ ) (graph 3$)$.

\begin{tabular}{cccc} 
& Group A & Group B & P Value \\
\hline Follow up & $15(9-18)$ & $16(10-20)$ & 0.274 \\
Median (IQR) & & & \\
\hline Recurrence & $4(13.3)$ & $1(6.3)$ & 0.645 \\
Pelvic wall & 3 & 0 & \\
Vaginal copula & 1 & 1 & \\
\hline
\end{tabular}

Table 5: Follow up and recurrence

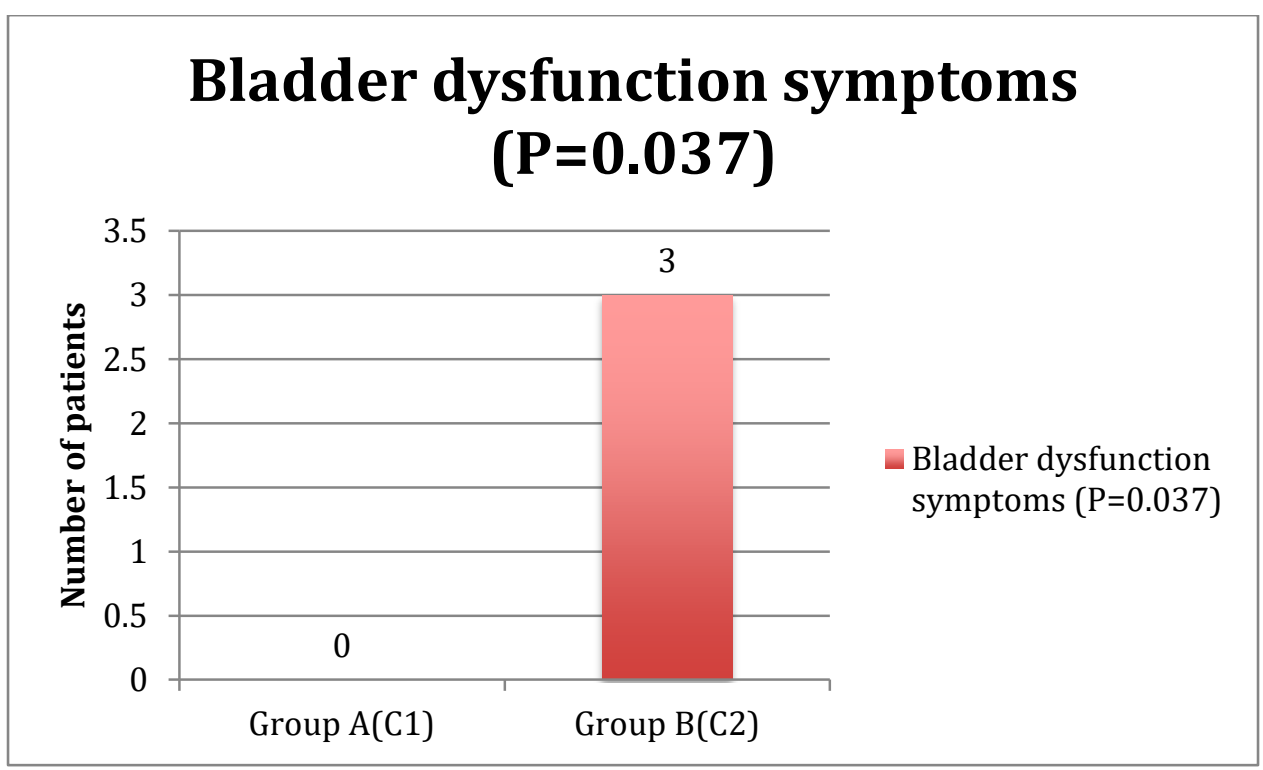

Graph 3: Bladder dysfunction symptoms during follow up.

\section{DISCUSSION}

Several trials published in the literature highlighted the benefits of nerve sparing technique combined with laparoscopy on the bladder function; Kavallaris et al(12) reported a PVR urine volume of less than $50 \mathrm{ml}$ on $3 \mathrm{rd}$ day postoperative in all included 32 patients in his trail, Liang et al(10) reported a median duration of postoperative bladder catheterization of $7.42 \pm 2.35$ days in LNSRH group and $16.75 \pm 7.73$ days in conventional LRH group to obtain a PVR urine volume less than $50 \mathrm{ml}(\mathrm{P}<0.05)$, Chen et al $(13)$ and Shi et al(14) reported a mean duration of postoperative bladder catheterization of 11.03 and 10.22 days in LNRH groups vs 18.13 and 17.88 days in the conventional LRH group to achieve a PVR urine volume of less than 100 and $50 \mathrm{ml}$ respectively $(\mathrm{P}<0.001)$. Zhang et al(15) reported the percentage of cases with PVR urine volume more than $100 \mathrm{ml}$ after 7 days postoperative which was $11 \%$ in LNSRH group and $64 \%$ in conventional LRH group $(\mathrm{P}=0.05)$. Bogani et al(16) reported a period of 
postoperative bladder catheterization of median 3.5 days in LNSRH group and 5.5 days in conventional LRH group $(\mathrm{P}=0.01)$.

In our study we reported a median duration of postoperative bladder catheterization 3.5 (3-5) days after LNSRH and 6(4-8.5) days after type $\mathrm{C} 2$ radical hysterectomy to achieve a PVR urine volume less than $100 \mathrm{ml}(\mathrm{P}=0.002)$, which is in concordance with other studies results in the literature.

According to the operative time 4 laparoscopic non-randomized studies(10, 15, $17,18)$ reported a statistically significant longer operating time in LNSRH than in conventional LRH groups $(\mathrm{P}=0.03)$. Shi et al $(14)$ reported insignificant difference in the operative time between the LNSRH and LRH groups $(\mathrm{P}=0.26)$. Bogani et al(16) reported a shorter median operating time in LNSRH group (210 minutes) than in conventional LRH group (257 minutes) with a statistically significant $\mathrm{p}$ value $(\mathrm{P}=0.005)$. In our study we report a significantly longer operating time in the non nerve sparing group (type $\mathrm{C} 2$ hysterectomy) than in LNSRH group (P 0.004) and this may be attributed to the relative advanced staging of cases included in the non nerve sparing group than the cases in LNSRH group which may cause a relative difficulty in dissection of the parametria in the non nerve sparing group.

The same previous 6 studies reported insignificant difference in blood loss between the LNSRH groups and the conventional LRH groups, which is in concordance with our study results.

Chen et al(18) reported no significant difference between the rate of intraoperative complications between LNSRH and conventional LRH groups with zero percent in both groups. Liang et al(10) reported $1.2 \%$ incidence of intraoperative complications in conventional LRH group and zero percent in LNSRH group with no statistically significant difference between both groups. Bogani et al(16) reported no significant difference between the rate of intraoperative complications between both groups (P 0.54) with no intraoperative complications in LNSRH group and 5\% incidence in conventional LRH group. Shi et al(14) reported $3.12 \%$ incidence of intraoperative complications in LNSRH group and $7.14 \%$ in conventional LRH group with no significant statistical difference. In our study there was no statistically significant difference in the rate of intraoperative complications between both groups (P>0.05) with $10 \%$ incidence in LNSRH group and $12.5 \%$ incidence in non-nerve sparing LRH group. Our rate of intraoperative complications is slightly higher in both groups than reported in other comparative studies in the literature, which may be attributed to the relative small sample size of our study.

As regard the postoperative complications; Lu et al(17) reported incidence of postoperative complications of $26.7 \%$ in LNSRH group and $33 \%$ in LRH group with no statistically significant difference. Bogani et al(16) recorded $3 \%$ incidence of at least grade 3 postoperative complications in the LNSRH group in comparison to $8 \%$ in the LRH group with insignificant $\mathrm{P}$ value. Shi et al(14) reported $0 \%$ incidence of postoperative complications in the LNSRH group and $2.3 \%$ incidence in the LRH group after a period of follow up of 2 months and the difference was not statistically significant. In our study we divided the postoperative complications into early complications within 30 days postoperatively and late complications which occurred more than one month after the operation and we reported $0 \%$ incidence in the LNSRH group and $12.5 \%$ incidence in the LRH group as regard the early postoperative complications and $3.3 \%$ vs $31.25 \%$ incidence as regard the late postoperative complications including the bladder dysfunction related complications. The total rate of postoperative complications was $3.3 \%$ in the LNSRH group and $37.5 \%$ in the conventional LRH group, which was statistically significant, and this may be attributed to relative advanced stage in the LRH group patients and including the long term urological complications in the late postoperative complications. 
Chen et al(18) reported a $0 \%$ recurrence and mortality rate after a follow up period of range 11-19 months in both LNSRH and LRH groups. Liang et al (10) did not report any cases of recurrence or mortality with a median follow up period of 22.3 months in both LNSRH and LRH groups. Bogani et al (16) reported a $6 \%$ local and regional recurrence rate in LNSRH group and $9.5 \%$ in LRH group within 3 years after the surgery with no statistical significance between both groups. The rate of distant metastasis was $9 \%$ in the LNSRH group and $10 \%$ in the LRH group which was not statistically significant however the median period of follow up in both groups was 26.9 months in LNSRH group and 65.9 months in LRH group with $\mathrm{P}<0.001$. Shi et al(14) after a median duration of follow up of 33.97 months in LNSRH group and 33.90 months in LRH group reported $9.3 \%$ recurrence rate in LNSRH group and $11.9 \%$ recurrence rate in the LRH group with no statistical significant difference between both groups. In our study we reported a recurrence rate of $13.3 \%$ in the LNSRH group after a median follow up period of 15 months and $6.3 \%$ in the conventional LRH group after a median follow up period of 16 months with no statistically significant difference between both groups.

\section{CONCLUSION}

Our study results supported the feasibility of LNSRH technique with better functional outcome without compromising the oncologic safety of the procedure however our work was relatively on a small sized sample of patients so we suggest the conduction of future prospective randomized controlled trials with a larger sample size.

\section{REFERENCES}

1. Querleu D, Morrow CP. Classification of radical hysterectomy. The Lancet Oncology. 2008;9(3):297-303.

2. Rob L, Halaska M, Robova H. Nervesparing and individually tailored surgery for cervical cancer. The Lancet Oncology. 2010;11(3):292-301.

3. Wertheim E. The extended abdominal operation for carcinoma uteri (based on 500 operative cases). Am J Obstet Dis Women Child. 1912;66:169-232.

4. Yabuki Y, Sasaki H, Hatakeyama N, Murakami G. Discrepancies between classic anatomy and modern gynecologic surgery on pelvic connective tissue structure: harmonization of those concepts by collaborative cadaver dissection. Am J Obstet Gynecol. 2005;193(1):7-15.

5. Kobayashi T. Abdominal radical hysterectomy with pelvic lymphadenectomy for cancer of cervix. Tokyo: Nanzando1961. p. $178-87$.

6. Raspagliesi F, Ditto A, Fontanelli R, Solima E, Hanozet F, Zanaboni F, et al. Nervesparing radical hysterectomy: a surgical technique for preserving the autonomic hypogastric nerve. Gynecologic oncology. 2004;93(2):307-14.

7. Kato T, Murakami G, Yabuki Y. A new perspective on nerve-sparing radical hysterectomy: nerve topography and overpreservation of the cardinal ligament. Japanese journal of clinical oncology. 2003;33(11):589-91.

8. Hockel M, Konerding MA, Heussel CP. Liposuction-assisted nerve-sparing extended radical hysterectomy: oncologic rationale, surgical anatomy, and feasibility study. Am J Obstet Gynecol. 1998;178(5):971-6.

9. Yabuki Y, Asamoto A, Hoshiba T, Nishimoto H, Kitamura S. Dissection of the cardinal ligament in radical hysterectomy for cervical cancer with emphasis on the lateral ligament. Am J Obstet Gynecol. 1991;164(1 Pt 1):7-14.

10. Liang Z, Chen Y, Xu H, Li Y, Wang D. Laparoscopic nerve-sparing radical hysterectomy with fascia space dissection technique for cervical cancer: description of technique and outcomes. Gynecologic oncology. 2010;119(2):202-7.

11. Possover M, Quakernack J, Chiantera V. The LANN technique to reduce postoperative functional morbidity in laparoscopic radical pelvic surgery. Journal of the American College of Surgeons. 2005;201(6):913-7. 
12. Kavallaris A, Hornemann A, Chalvatzas N, Luedders D, Diedrich K, Bohlmann MK. Laparoscopic nerve-sparing radical hysterectomy: description of the technique and patients' outcome. Gynecologic oncology. 2010;119(2):198-201.

13. Chen L, Zhang WN, Zhang SM, Yang $\mathrm{ZH}$, Zhang P. Effect of laparoscopic nervesparing radical hysterectomy on bladder function, intestinal function recovery and quality of sexual life in patients with cervical carcinoma. Asian Pacific journal of cancer prevention : APJCP. 2014;15(24):10971-5.

14. Shi R, Wei W, Jiang P. Laparoscopic Nerve-Sparing Radical Hysterectomy for Cervical Carcinoma: Emphasis on Nerve Content in Removed Cardinal Ligaments. International journal of gynecological cancer : official journal of the International Gynecological Cancer Society. 2016;26(1):192-8.

15. Zhang Y, Wang D, Ma Y, Pan C. A clinical study of surgical treatment of the cervical cancer with laparoscopic nerve sparing radical hysterectomy. Progress in obstetrics and gynecology. 2010;19:31-2.

16. Bogani G, Cromi A, Uccella S, Serati M, Casarin J, Pinelli C, et al. Nerve-sparing versus conventional laparoscopic radical hysterectomy: a minimum 12 months' follow-up study. International journal of gynecological cancer : official journal of the International Gynecological Cancer Society. 2014;24(4):787-93.

17. LU Y, YAO D-s, MO L-z, Fei L, PAN Z-m. Preliminary clinical study of laparoscopic pelvic autonomic nerve-plane sparing radical hysterectomy. Chinese Clinical Oncology. 2012;1(17):347-51.

18. Chen Y, Li Y, Xu HC, Li JN, Li YY, Liang ZQ. [Laparoscopic anatomical nerve sparing radical hysterectomy for cervical cancer: a clinical analysis of 37 cases]. Zhonghua fu chan ke za zhi. 2009;44(5):359-63. 